\title{
Project portfolio selection for increasing sustainability in supply chains
}

\author{
María-José Verdecho* • David Pérez-Perales • Faustino Alarcón-Valero \\ Dep. Business Organisation. Research Centre on Production Management and \\ Engineering (CIGIP), Universitat Politècnica de València, Valencia, Spain
}

Received: 19 February 2020

Revised: 19 June 2020

Accepted: 20 June 2020

\begin{abstract}
Sustainability practices impact on the competitiveness of organizations. Enterprises need approaches that both support the implementation of these practices by helping to define the strategic elements of sustainable supply chains and prioritize projects to increase profitability. The purpose of this paper is to propose an approach using the Analytic Hierarchy Process that supports the portfolio project decision by aligning the project selection process to the strategic objectives of a supply chain that pursue sustainability. This approach will benefit enterprises to prioritize projects that have the highest impact on the sustainability strategy of the supply chain over time. The approach has been applied to an Agri-food supply chain.
\end{abstract}

Keywords: strategy; sustainability; agri-food supply chains; program evaluation JEL Classification Codes: M11

\section{Introduction}

Project portfolio selection is a strategic activity consisting of prioritizing projects to be implemented within an organization according to their alignment with the strategy, considering the limited resources of organizations. Portfolio selection is a process where organizations select the most relevant projects in order to provide alignment between project implementation and strategy completion in order to increase the impact on their competitiveness.

As regards strategy completion, Performance Management Systems (PMSs) are approaches to support the development and deployment of the strategy of organizations from the top level (strategic) to the bottom level (operational). Since the development of the best known PMS for organizations, the Balanced ScoreCard (BSC) by Kaplan and Norton (1992), other PMSs have been defined for supply chain contexts. Some of these extended BSCs for supply chains are: Brewer and Speh (2000), Bititci et al. (2005), Folan and Browne (2005), Alfaro et al. (2007), Alfaro et al. (2010), Verdecho et al. (2012), Verdecho et al. (2020), etc. The elements that

\footnotetext{
* Corresponding author. E-mail: mverdecho@ cigip.upv.es.

Citation: Verdecho, M. J., Pérez-Perales, D., and Alarcón-Valero, F. (2020) Project portfolio selection for increasing sustainability in supply chains, Economics and Business Letters, 9(4), 317-325.
}

DOI: $10.17811 /$ ebl.9.4.2020.317-325 
compose a BSC are objectives, key performance indicators, initiatives, etc. All these elements are defined for different perspectives, such as the four classical perspectives of the BSC (Kaplan and Norton, 1992): financial, customer, process, and innovation and learning.

In addition, supply chains should focus on being sustainable. Ahi and Searcy (2013) define sustainable supply chain management as the creation of coordinated supply chains through the voluntary integration of economic, environmental, and social considerations with key interorganizational business systems designed to efficiently and effectively manage the material, information, and capital flows associated with the procurement, production, and distribution of products or services in order to meet stakeholder requirements and improve the profitability, competitiveness, and resilience of the organization over the short- and long-term '. This definition integrates the management of the three pillars of sustainable development (economic, environmental and social) with the management of the business of supply chains which can be performed by using PMSs. Then, both elements should be integrated by using a PMS to manage sustainable supply chains.

The process of portfolio selection is a multi-criteria problem that has been analyzed in the literature (Begičević et al., 2010; Toloo et al., 2018). The selection and implementation of the most relevant projects is related to strategy completion. Then, if supply chains pursue the achievement of the strategic objectives, the portfolio selection process should be aligned with it in order to increase the synergies in the supply chain performance obtained. These objectives are better managed when using a PMS and this PMS should involve managing the sustainability pillars in order to perform a portfolio selection process that increases sustainability in the supply chain.

In the literature, several models have been developed combining the BSC with multi-criteria decision analysis (MCDA) methods for project selection (Yao and Liu, 2016; Scheiblich et al., 2017; Basar, 2019). However, in these models, the inclusion of the environmental and social pillars of sustainability has been overlooked. Only one paper, Chang (2015), includes some social criteria in the proposal but the model neither considers the environmental pillar nor defines a strategic BSC for supply chains. It is a specific BSC for project selection. To solve this gap, this paper proposes a strategic BSC-MCDA model that integrates the three dimensions of sustainability with the portfolio selection decision by aligning the project selection to the strategic objectives of a supply chain. This approach will help enterprises to prioritize projects that have the highest impact on the strategy of the supply chain and their sustainability over time.

This paper is structured in the following sections. Section 2 presents a literature review of portfolio selection models developed using MCDA techniques and, specifically, using the BSCMCDA combination. This last case analyses whether the models integrate environmental and social objectives in the BSC. Section 3 sets out the multi-criteria approach to select projects for sustainable supply chains. Section 4 develops an application of the approach to an agri-food supply chain. Finally, concluding remarks are presented.

\section{Background}

\subsection{Multi-criteria decision analysis for project selection}

Multi-criteria decision analysis (MCDA) techniques have been applied in multiple decisionmaking problems for project selection using both multi-objective and multi-attribute methods. Danila (1989) presents a review on research and development project evaluation and selection methodologies and techniques.

Gutjahr et al. (2008) develop a model using heuristics and metaheuristics that seeks to maximize a weighted average of economic gains from projects and strategic gains from the increment of desirable competencies. Toolo et al (2018) use Data Envelopment Analysis (DEA) to select the most efficient information system projects in presence of user subjective opinions. 
Other multi-attribute techniques, such as Promethee and Electre, have also been applied for project selection. Halouani et al. (2009) uses Promethee for project selection, and Buchanan and Vanderpooten (2007) rank projects for an electricity utility using Electre.

The Analytic Hierarchy Process (AHP) and Analytic Network process (ANP) developed by Saaty (1980) have also been used for project selection. Subramanian and Ramnathan (2012) develop a review of AHP applications in operations management, including project portfolio selection. Lee et al (2007) propose an AHP model to select wind farms. Su and Chou (2008) develop an AHP model for the creation of six sigma projects on a semiconductor company. Aragonés-Beltrán et al (2010) present an ANP model for the selection of photovoltaic solar power plant investment projects. Begičević et al (2010) propose a prioritization of projects in higher education institutions using ANP. Bai and Zhan (2011) set out an ANP model for IT project selection and apply it to an oils and food company in China. Smith-Perera et al. (2010) develop an ANP model for portfolio selection in an electrical company.

In addition, some recent papers (Khalili-Damghani and Sadi-Nezhad 2013; Kudratova et al. 2018; Ibrahim and Shaker 2019) have developed MCDA models that include sustainability criteria (environmental and/or social criteria) for the purposes of electing projects, but these models are not structured using a BSC.

\subsection{BSC and multi-criteria decision analysis for project selection}

Several papers have used BSC combined with MCDA methods for project selection. Table 1 presents a summary of these studies. The table shows three characteristics: the use of the BSC, the environmental and social dimensions of sustainability and the MCDA tools. The economic dimension of sustainability is not specified as it is already considered in the financial perspective of the BSC. Then, all the papers already cover the economic dimension. Asosheh et al. (2010) apply DEA with the BSC to develop a new method for IT project selection. Chang (2013) develops a BSC-TOPSIS model for new product development project selection. Wu et al. (2013) sets out a BSC-ANP model for new product development projects. Ravasan et al. (2014) use BSC with fuzzy TOPSIS (FTOPSIS) for project selection. Wu et al. (2014) apply BSC using an interval-valued intuitive fuzzy decision-making method based on improved TOPSIS in new energy project priority selection. Chang (2015) propose a project selection model for non-profit TV stations using BSC-ANP-TOPSIS. García-Melón et al. (2015) propose a BSC model using ANP for the selection of portfolio projects applied to a public Venezuelan Power Corporation. Liang (2015) proposes a BSC-FAHP model for information systems performance assessment. Tabrizi et al. (2016) develop a BSC project portfolio selection model using fuzzy DEMATEL and multi-choice goal programming (MCGP). Wudhikarn (2016) applies BSC-ANP-ZOGP for strategic project selection. Kao et al. (2016) apply BSC-FAHP to select construction projects. Yao and Liu (2016) develop a BSC-AHP model for e-government project evaluation. Scheiblich et al. (2017) develop a BSC model using the weighted sum to measure the performance of project management. Basar (2019) uses the fuzzy operator and BSC for the performance evaluation of IT projects.

As regards sustainability criteria, specifically environmental and social criteria, only one paper, Chang (2015), includes the social criteria in the proposal, but the model neither considers the environmental dimension of sustainability nor defines a strategic BSC for supply chains. It is a specific BSC for project selection. The literature does not present any BSC-MCDA model that integrates the three dimensions of sustainability into a strategic BSC for project selection. The objective of this paper is to develop a proposal to fill this gap. With it, organizations will have a tool to increase their sustainability and competitiveness by aligning the project selection and implementation with the main strategic objectives. 
Table 1. Review of papers using BSC-MCDA and sustainability dimensions for project selection.

\begin{tabular}{|c|c|c|c|c|}
\hline \multirow[b]{2}{*}{ References } & \multicolumn{3}{|c|}{ Sustainability } & \multirow[b]{2}{*}{ MCDA } \\
\hline & BSC & Environmental & Social & \\
\hline Asosheh et al (2010) & $\mathrm{X}$ & & & DEA \\
\hline Chang (2013) & $\mathrm{X}$ & & & TOPSIS \\
\hline Wu et al. (2013) & $\mathrm{X}$ & & & ANP \\
\hline Ravasan et al. (2014) & $\mathrm{X}$ & & & FTOPSIS \\
\hline Wu et al. (2014) & $\mathrm{X}$ & & & FTOPSIS \\
\hline Chang (2015) & $\mathrm{X}$ & & $\mathrm{X}$ & ANP-TOPSIS \\
\hline García-Melón et al. (2015) & $\mathrm{X}$ & & & ANP \\
\hline Liang (2015) & $\mathrm{X}$ & & & FAHP \\
\hline Tabrizi et al. (2016) & $\mathrm{X}$ & & & FDEMATEL-MCGP \\
\hline Wudhikarn (2016) & $\mathrm{X}$ & & & ANP-ZOGP \\
\hline Kao et al. (2016) & $\mathrm{X}$ & & & FAHP \\
\hline Yao and Liu (2016) & $\mathrm{X}$ & & & AHP \\
\hline Scheiblich et al. (2017) & $\mathrm{X}$ & & & Weighted sum \\
\hline Basar (2019) & $X$ & & & Fuzzy Operator \\
\hline
\end{tabular}

\section{The multi-criteria approach to select projects for sustainable supply chains}

The approach comprises eight phases. Phase 1 comprises the development of the PMS for supply chain management. The supply chain may already have developed a PMS; if so, this step will not be needed. The PMS may involve the four classical perspectives of Kaplan and Norton (1992) (financial, customer, business process, and innovation and learning perspectives) but sometimes these perspectives are adapted in inter-organizational contexts, such as in the PMSs by Brewer and Speh (2000), Bititci et al. (2005) and Folan and Browne (2005).

Phase 2 involves the sustainability analysis of the environmentally and socially relevant aspects to discover how to integrate environmental and social measurements within the strategy of the supply chain. The literature contains different structures to introduce environmental and social objectives into a BSC (Figge et al., 2002; Qorri et al. 2018). Figge et al. (2002) classify these BSC structures and can be used to guide the BSC scheme selection in this phase.

Phase 3 develops the performance structure to include the measurement/management of the sustainability elements within an integrated PMS.

Phase 4 consists of the identification of the projects to be assessed.

In Phase 5, the multi-criteria method, AHP, is applied to define the model. The Analytic Hierarchy Process (AHP) structures the model through a hierarchy of levels linked by relationships (Saaty, 1980). The top level consists of the ultimate goal of the model. The next level down shows the criteria that will help to achieve that ultimate goal. Then, the decomposition of these criteria into attributes is developed in the next levels. The last level shows the alternatives (projects to be prioritized in this case). Fig. 1 shows the BSC-AHP model for project selection structured in three levels: the sustainable supply chain (ultimate goal of the model), the Balanced Scorecard Performance Elements (PE) for sustainability management; and projects (alternatives).

In Phase 6, decision makers perform pairwise comparisons by using the fundamental scale of Saaty (1980) and local priorities are computed.

In Phase 7, the global priorities are obtained and the prioritization of the alternatives is provided.

Finally, in Phase 8, the analysis of results is performed to analyze whether the solution obtained is robust enough when changes to the preferences of decision makers occur. 
Figure 1. AHP model for project selection in sustainable supply chains.

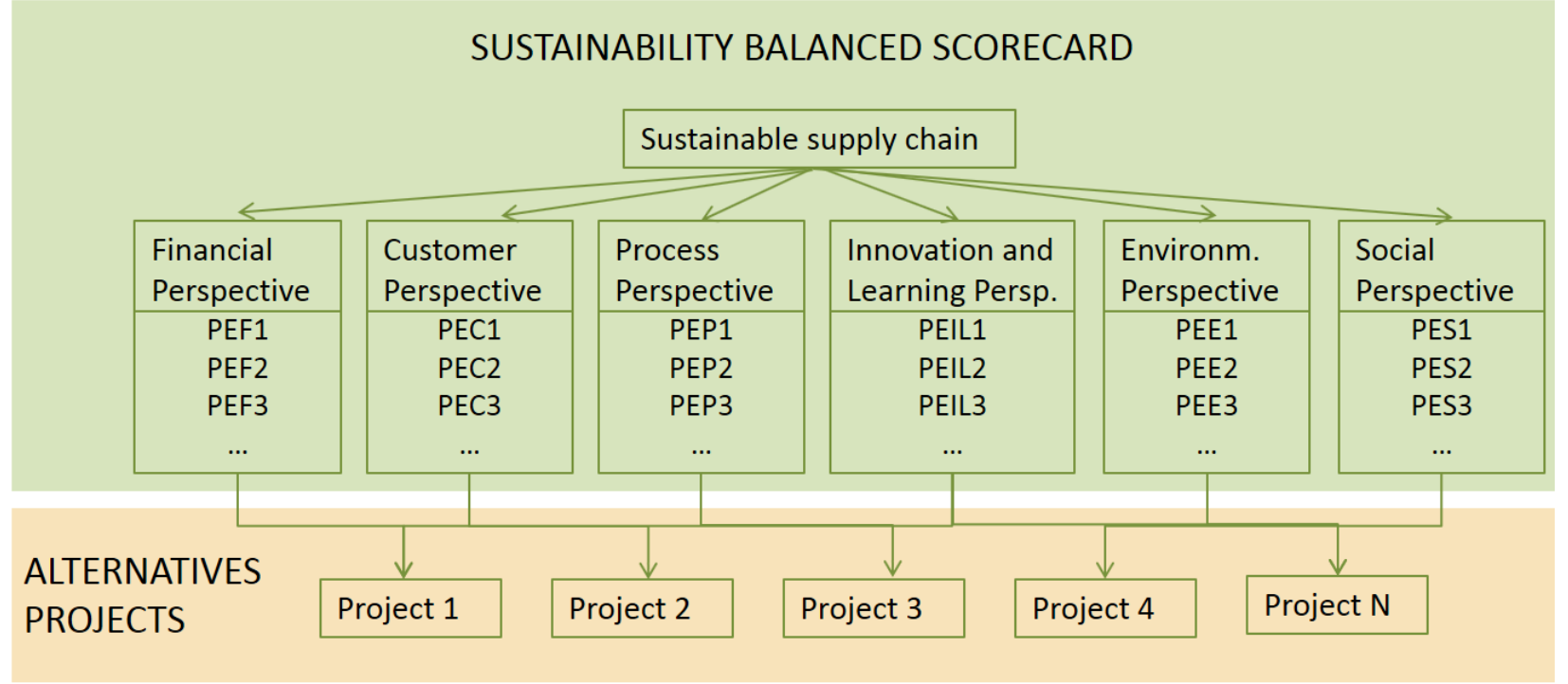

\section{Data and results}

The methodology has been used to prioritize projects within an agri-food supply chain. The supply chain had defined its strategy developing specific objectives and key performance indicators but they were not using a BSC approach and nor had they defined strategic objectives for the environmental and social dimensions of sustainability. Then, it has been necessary to adapt the strategic information into a BSC scheme as well as include the sustainability dimensions. After reviewing the different options proposed by Figge et al. (2002) with the experts of the supply chain (production manager and supply chain manager), it was agreed to use a six-perspective structure (the four classical BSC perspectives and the environmental and social perspectives). Two meetings of 2 hours each were held with the experts to define the strategic elements (objectives and KPIs in each perspective) of the BSC (see Table 2) and the list of strategic projects to assess. Table 2 shows the objectives and KPIs defined for the financial, customer, process, environmental and social perspectives.

As for the alternatives, a list of seven projects (P1-P7) was identified regarding strategic themes such as:

- P1. Optimization of field assignment to different fruits

- P2. Crop rotation

- P3. Labour improvement

- P4. Improvement of fruit quality

- P5. Joint project development with research centres

- P6. Pest management

- P7. Cost improvement

Once the BSC was defined, the different elements were structured in an AHP model linking the different projects to the BSC. The model was developed using Superdecisions software. The experts held two additional meetings of 1.5 hours each to perform the pairwise comparison matrices using the fundamental scale of Saaty (1980). Then, the software computed the local priorities and the consistency of the judgments. Table 3 presents the local priorities coming from the pairwise comparison matrix of the list of projects with respect to the increase taste objective. The consistency ratio is also checked (6.94\%). In this case, the results are acceptable according to Saaty (1980). 
Table 2. Agri-food supply chain BSC.

\begin{tabular}{|c|c|c|}
\hline Perspectives & Objectives & KPIs \\
\hline \multirow{5}{*}{ Financial } & Increase profitability & KPI1 = \% ROI variation \\
\hline & Increase margin & $\mathrm{KPI} 2=\%$ variable cost reduction \\
\hline & & $\mathrm{KPI} 3=\%$ fixed cost reduction \\
\hline & & $\mathrm{KPI} 4=\%$ price variation per fruit variety \\
\hline & Reduce production cost & $\mathrm{KPI} 5=\%$ variation of production cost \\
\hline \multirow{5}{*}{ Customer } & Increase satisfaction & KPI6 $=\%$ customer satisfaction \\
\hline & & $\mathrm{KPI} 7=\%$ backorders \\
\hline & & KPI8 $=\%$ lost sales \\
\hline & & $\mathrm{KPI} 9=\%$ complaints \\
\hline & Increase perceived quality & $\mathrm{KPI} 10=\%$ perceived quality \\
\hline \multirow{6}{*}{ Process } & Increase fill rate & KPI11 = \% variation fill rate \\
\hline & Increase safety & $\begin{array}{l}\text { KPI } 12=\% \text { reduction in non-conformance products } \\
\text { according to requirements }\end{array}$ \\
\hline & Increase storage & KPI13= \% shelf life \\
\hline & characteristics & $\mathrm{KPI} 14=\%$ taste improvement \\
\hline & Increase taste & KPI15 $=\%$ crop yield \\
\hline & Increase crop yield & \\
\hline \multirow[t]{5}{*}{ Environmental } & Reduce consumption & KPI16 $=\%$ water consumption \\
\hline & & KPI17= \% energy consumption \\
\hline & & KPI18 $=\%$ re-use consumption \\
\hline & Reduce pollution & KPI19 = Chemical reduction \\
\hline & $\begin{array}{l}\text { Obtain environmental } \\
\text { certification }\end{array}$ & $\begin{array}{l}\text { KPI20 = Environmental management system } \\
\text { certification }\end{array}$ \\
\hline \multirow[t]{2}{*}{ Social } & Improve employment & $\begin{array}{l}\text { KPI } 21=\% \text { improvement of employee contracts } \\
\text { KPI } 22=\% \text { job rotation }\end{array}$ \\
\hline & $\begin{array}{l}\text { Increase Health \& safety } \\
\text { culture }\end{array}$ & $\mathrm{KPI} 23=\%$ training hours per employee \\
\hline
\end{tabular}

Table 3. Project pairwise comparison matrix wrt the increase taste objective.

\begin{tabular}{lrrrrrrrr}
\hline \hline & P1 & P2 & P3 & P4 & P5 & P6 & P7 & Priorities \\
\hline P1 & 1 & $1 / 3$ & $1 / 5$ & $1 / 9$ & $1 / 5$ & 1 & 1 & 0.0360 \\
P2 & 3 & 1 & 5 & $1 / 5$ & $1 / 3$ & 5 & 5 & 0.1474 \\
P3 & 5 & $1 / 5$ & 1 & $1 / 9$ & $1 / 5$ & 1 & 1 & 0.0587 \\
P4 & 9 & 5 & 9 & 1 & 3 & 9 & 9 & 0.4548 \\
P5 & 5 & 3 & 5 & $1 / 3$ & 1 & 5 & 5 & 0.2238 \\
P6 & 1 & $1 / 5$ & 1 & $1 / 9$ & $1 / 5$ & 1 & 1 & 0.0396 \\
P7 & 1 & $1 / 5$ & 1 & $1 / 9$ & $1 / 5$ & 1 & 1 & 0.0396 \\
\hline & & & & & & & C.R. & $6,94 \%$ \\
\hline \hline
\end{tabular}

Similarly, the rest of the pairwise comparison matrices were computed for the remaining projects with respect to the different BSC objectives. Then, the overall priorities were computed. The three projects with the greatest impact on supply chain sustainability are: Improvement of fruit quality (P4), Optimization of field assignment to different fruits (P1), and Cost improvement (P7). This project prioritization ranking is consistent with the opinion of decision makers as these three projects are considered the most relevant in the short term, while the rest of the projects have a medium-term projection for the supply chain strategy. A sensitivity analysis performed using Superdecisions software confirms that the solution obtained is robust. 


\section{Concluding remarks}

Several models have been developed in the literature for portfolio selection. Some of them integrate the BSC with MCDA methods to prioritize proposals for project selection. However, the literature lacks a model that integrates the BSC with the environmental and social dimensions of sustainability to foster the competitiveness of supply chains by introducing sustainability into its strategy. This paper proposes an approach to fill this gap.

Then, this study presents an approach to deal with this problem by using an AHP model that links project selection to a supply chain, BSC, that integrates the dimensions of sustainability. With this methodology, the supply chain can benefit from: 1) providing a strategic tool (Balanced Scorecard) to implement the sustainability management within the supply chain, 2) developing a feedback analysis to analyze the progression of the supply chain towards the sustainable goals, 3 ) structuring a decision model that prioritizes the portfolio selection aligned to the sustainability of strategic objectives of the supply chain, and 4) including decision makers of the supply chain in every phase of the approach to validate the results. This approach has been applied to an agri-food supply chain. Sensitive analysis concludes that the solution achieved is robust.

This paper presents some limitations. The research was based on peer-reviewed indexed journals from Scopus published in English. Publications from books, chapters, conferences or doctoral dissertations were not considered. The keywords were defined to cover the whole set of words used, but the use of synonyms in the papers could limit the inclusion of articles for the analysis. As for validation, the proposal has so far only been applied to a case study. It is necessary to extend its application to other cases and types of supply chains to obtain feedback in order to improve the approach. Future studies will extend this approach by using it in other case studies and it will compare results obtained using other MCDA methods as well as uncertainty techniques.

\section{Acknowledgments}

Authors of this publication acknowledge the contribution of the Project GV/2017/065 'Development of a decision support tool for the management and improvement of sustainability in supply chains' funded by the Regional Government of Valencia.

\section{References}

Ahi, P., Searcy, C. (2013) A comparative literature analysis of definitions for green and sustainable supply chain management, Journal of Cleaner Production, 52, 329-341.

Alfaro, JJ., Ortiz, A., Rodríguez, R. (2007) Performance measurement system for Enterprise Networks, International Journal of Productivity and Performance Management, 56(4), 305334.

Alfaro, JJ., Rodriguez, R., Ortiz, A., Verdecho, MJ. (2010) An Information Architecture for a Global Performance Management Framework, Computers in Industry, 61(7), 676 - 685.

Aragonés-Beltrán, P., Chaparro-González, F., Pastor-Ferrando, J.P., Rodríguez-Pozo, F. (2010) An ANP-based approach for the selection of photovoltaic solar power plant investment projects, Renewable and Sustainable Energy Reviews, 14(1), 249-264.

Asosheh, A, Nalchigarb, S., Jamporazmey, M. (2010) Information technology project evaluation: An integrated data envelopment analysis and balanced scorecard approach, Expert Systems with Applications, 37(8), 5931-5938.

Bai, H., Zhan, Z., (2011) An IT Project selection method based on fuzzy analytic network process 2011 International Conference on System science, Engineering design and Manufacturing informatization, Guiyang, 275-279. 
Basar, A. (2019) A novel methodology for performance evaluation of IT projects in a fuzzy environment: a case study, Soft computing, Article in press.

Begičević, N., Divjak, B., Hunjak, T. (2010) Decision-making on prioritization of projects in higher education institutions using the analytic network process approach, Central European Journal of Operations Research, 18, 341-364.

Bititci, U.S., Mendibil, K., Martinez, V., Albores, P. (2005) Measuring and managing performance in extended enterprises, International Journal of Operations \& Production Management, 25(4), 333-353.

Brewer, P.C., Speh, T.W. (2000) Using the Balanced ScoreCard to measure supply chain performance, Journal of Business Logistics, 21(1), 75-93.

Buchanan, J., Vanderpooten, D. (2007) Ranking projects for an electricity utility using ELECTRE III, International Transactions in Operational Research, 14(4), 309-323.

Chang, K.L. (2013) Combined MCDM approaches for century-old Taiwanese food firm new product development project selection, British Food Journal, 115(8), 1197-1210.

Chang, K.L. (2015) A Hybrid program projects selection model for nonprofit TV stations, Mathematical Problems in Engineering, Article number 368212.

Danila, N. (1989) Strategic evaluation and selection of R\&D projects, $R \& D$ Management, 19(1).

Figge, F., Hahn, T., Schaltegger, S., Wagner, M. (2002) The sustainability balanced scorecard: linking sustainability management to business strategy, Business Strategy and Environment, 11, 269-284.

Folan, P.; Browne, J. (2005) Development of an Extended Enterprise Performance Measurement System, Production Planning and Control, 16(6), 531-544.

García-Melón, M., Poveda-Bautista, R., Del Valle, JL. (2015) Using the strategic relative alignment index for the selection of portfolio projects application to a public Venezuelan Power Corporation, International Journal Production Economics, 170, 54-66.

Gutjahr, WJ., Katzensteiner, S., Reiter, P., Stummer, C., Denk, M. (2008) Competence-driven project portfolio selection, scheduling and staff assignment, Central European Journal of Operations Research, 16, 281-306.

Halouani, N., Chabchoub, H., Martel, JM. (2009) PROMETHEE-MD-2T method for project selection, European Journal of Operational Research, 195(3), 841-849.

Ibrahim, A.H., Shaker, M.A. (2019) Sustainability index for highway construction projects, Alexandria Engineering Journal, 58(4), 1399-1411.

Kao, C.H., Huang, C.H., Hsu, S.C., Tsai, I.H. (2016) Success factors for Taiwanese contractors collaborating with local Chinese contractors in construction projects, Journal of Business Economics and Management, 17(6), 1007-1021.

Kaplan, R.S., Norton, D.P. (1992) The balanced scorecard - measures that drive performance, Harvard Business Review, 70(1), 71-79.

Khalili-Damghani, K, Sadi-Nezhad S (2013) A decision support system for fuzzy multi-objective multi-period sustainable project selection, Computers \& Industrial Engineering, 64(4), 1045-1060.

Kudratova, S., Huang, X., Zhou, X. (2018) Sustainable project selection: Optimal project selection considering sustainability under reinvestment strategy, Journal of Cleaner Production, 203 (1), 469-481.

Lee AHI., Chen HH., Kang HY. (2008) Multi-criteria decision making on strategic selection of wind farms, Renewable Energy, 34(1), 120-126.

Liang, Y.H. (2015) Performance measurement of interorganizational information systems in the supply chain, International Journal of Production Research, 53(18), 5484-5499. 
Qorri, A., Mujki, Z., Kraslawski, A. (2018) A conceptual framework for measuring sustainability performance of supply chains, Journal of Cleaner Production, 189, 570-584.

Ravasan, A.Z., Mansouri, T., Mohammadi, M.M., Rouhani, S. (2014) Supporting the module sequencing decision in ITIL solution implementation: An application of the fuzzy TOPSIS approach, International Journal of Information Technologies and Systems Approach, 7(2), 41-60.

Saaty, T.L. (1980) The Analytic Hierarchy Process, McGraw-Hill: New York.

Scheiblich, M., Maftei, M.Email Author, Just, V., Studeny, M. (2017) Developing a project scorecard to measure the performance of project management in relation to EFQM excellence model, Amfiteatru Economic, 19(11), 966-980.

Smith-Perera A., García-Melón, M., Poveda-Bautista, R., Pastor-Ferrando, JP (2010) A Project Strategic Index proposal for portfolio selection in electrical company based on the Analytic Network Process, Renewable and Sustainable Energy Reviews, 14, 6, 1569-1579.

Subramaniana N., Ramakrishnan, R. (2012) A review of applications of Analytic Hierarchy Process in operations management, International Journal of Production Economics, 138(2), 215-241.

Su, C.T., Chou, C.J. (2008) A systematic methodology for the creation of six sigma projects: a case study of semiconductor foundry, Expert Systems with Applications, 34, 2693-2703.

Tabrizi, B.H., Torabi, S.A., Ghaderi, S.F. (2016) A novel project portfolio selection framework: An application of fuzzy DEMATEL and multi-choice goal programming, Scientia Iranica, 23(6), 2945-2958.

Toolo, M., Nalchigar, S., Sohrabi, B. (2018) Selecting most efficient information system projects in presence of user subjective opinions: a DEA approach, Central European Journal of Operations Research, 26, 1027-1051.

Verdecho, MJ., Alfaro-Saiz, JJ., Rodríguez-Rodríguez, R. (2012) Prioritization and management of inter-enterprise collaborative performance, Decision Support Systems, 53, 142-153.

Verdecho, MJ., Alarcón-Valero, F., Pérez-Perales, D., Alfaro-Saiz, JJ., Rodríguez-Rodríguez, R. (2020) A methodology to select suppliers to increase sustainability within supply chains, Central European Journal of Operations Research, Article in press.

Wu, G.D., Liao, S.K., Chiu, C.H., Chang, K.L. (2013) New product development projects selection for Taiwanese century-old businesses, Life Science Journal, 10(3), 1152-1161.

Wu, Y., Liu, C., Xu, H., Geng, S., Yang, Y. (2014) Application of interval-valued intuitive fuzzy decision-making method based on improved TOPSIS in new energy project priority selection, Energy Education Science and Technology Part A: Energy Science and Research, 32(6), 6829-6842.

Wudhikarn, R. (2016) An efficient resource allocation in strategic management using a novel hybrid method, Management Decision, 54(7), 1702-1731.

Yao J., Liu, J. (2016) E-Government Project Evaluation: A Balanced Scorecard Analysis, Journal of Electronic Commerce in Organizations, 14(1), 11-23. 